\title{
Total Knee Arthroplasty: Patellar Replacement's Influence in Patient Quality of Life Postoperatively
}

\section{Carlos Roberto Schwartsmann 1,2, Gabriel Severo da Silva², Ivan Fadanelli Simionato², Flávia Magalhães Nunes², Henrique Lammerhirt ${ }^{2}$, João Pedro Farina Brunelli², Leandro de Freitas Spinelli2}

${ }^{1}$ Federal University of Medical Sciences, Porto Alegre, Brazil

${ }^{2}$ Department of Orthopedics and Traumatology, Irmandade Santa Casa de Misericordia de Porto Alegre, Porto Alegre, Brazil

Email: schwartsmann@gmail.com

How to cite this paper: Schwartsmann, C.R., da Silva, G.S., Simionato, I.F., Nunes, F.M., Lammerhirt, H., Brunelli, J.P.F. and de Freitas Spinelli, L. (2017) Total Knee Arthroplasty: Patellar Replacement's Influence in Patient Quality of Life Postoperatively. Open Journal of Orthopedics, 7, 228234. https://doi.org/10.4236/ojo.2017.78024

Received: May 17, 2017

Accepted: July 28, 2017

Published: July 31, 2017

Copyright $\odot 2017$ by authors and Scientific Research Publishing Inc. This work is licensed under the Creative Commons Attribution International License (CC BY 4.0).

http://creativecommons.org/licenses/by/4.0/

(c) (i) Open Access

\begin{abstract}
Objective: To study the influence of patellar resurfacing on quality of life under a standardised score. The chosen score was the Knee Society Score (KSS), which considers range of motion, pain, contractors, alignment and stability. Methods: Retrospective review of 60 patients submitted to total knee arthroplasty (TKA) was divided into two groups: with patellar resurfacing (PR) and without patellar resurfacing (NPR). We reviewed data from these patients containing the KSS, which are routinely used in our service. Data were analysed from 2013 to 2014, with a minimal patient follow-up of 18 months. Results: There were no unsatisfactory scores in our study. Total scores (KSS) were similar between the groups (mean KSS: PR $=88.36 \pm 9.64 ; \mathrm{NPR}=84.26 \pm 9.44[p=0.1]$ ). While stratifying into groups (poor, fair, good, excellent), we found excellent results in $84.8 \%$ of PR versus $59.3 \%$ NPR $(p=0.056)$. These data did not reach statistical significance and can therefore be considered a coincidental result. Conclusion: Although these results did not show statistical significance $(p=0.056)$, patellar resurfacing patients tend to get more "excellent" results after 18 months of follow-up in quality of life when evaluated by KSS. Perhaps a larger amount of patients would suffice to acquire statistical significance in a future study.
\end{abstract}

\section{Keywords}

Knee Arthroplasty, Patella, Joint Instability, Quality of Life

\section{Introduction}

The increased elderly population is a worldwide reality that directly reflects the 
longer life expectancy. This phenomenon makes the study of quality of life in the aged population a very interesting matter for scientific research. Quality of life is directly linked to the presence of aged-related diseases, known as chronic non-transmissible diseases. The prevalence of articular degenerative diseases is increasing, and the knee joint is the most susceptible to osteoarthritis (OA) [1] [2].

$\mathrm{OA}$ is considered a public health issue as it is the most common articular disease and a major cause of functional incapacity, with an emphasis in women and the elderly. More than $80 \%$ of people with OA present limitations in their activities of daily living (ADL), such as mobility at home and outside and the execution of domestic and professional tasks, therefore compromising the quality of life and enhancing the risk of morbidity and mortality.

The treatment of OA must be directed to symptom relief, improved functionality and increased quality of life. Among the therapeutic alternatives there are non-drug, pharmacological and surgical treatments. When the success of nonsurgical treatment is no longer sufficient, one can opt for a Total Knee Arthroplasty (TKA).

TKA consists of replacing all three of the articular components of the knee (lateral femorotibial, medial femorotibialand patellofemoral) for a prosthetic joint in order to control the pain, realign the member and improve function. TKA and Total Hip Arthroplasty are the most successful procedures in the history of orthopaedics and one of the two most frequently performed ones because of the dramatic results in re-establishing joint function and symptom control. Nowadays, there are more anatomical designs of implants, allowing a greater duration of the "new joint" [3].

Patellar resurfacing in TKA is a controversial matter and has been discussed since its introduction. Conclusions in many studies were limited, with methodological failures and biases, meaning that the true value of the procedure is still constantly debated [4] [5].

Studies evaluating patient satisfaction after TKA estimate that $75 \%-89 \%$ of patients are satisfied postoperatively, while $11 \%-25 \%$ are not [6].

The main goal of this study was to evaluate the influence ofpatellar resurfacing versus non-resurfacing during TKA on quality of life in our patients.

\section{Materials and Methods}

In total, 60 patients submitted to Total Knee Arthroplasty in the Orthopaedics and Traumatology Service of Santa Casa de Misericórdia de PortoAlegre, Brazil, between 2013 and 2014, with a minimal patient follow-up of 18 months were included in this study. A retrospective cohort was formed by reviewing patient files randomly in the hospital; patients were divided into two groups: patellar resurfacing $(\mathrm{n}=33)$ and non-resurfacing $(\mathrm{n}=27)$. Sample size was calculated considering a significance level of 0.05 , standard deviation of 9.6, and power of $95 \%$, with a minimum of 24 patients. 
We analysed the quality of life using the Knee Society Score (KSS) postoperatively. This questionnaire is routinely applied in our service, as it is a standardised method, which has been validated in Portuguese [7]. The objective knee score, completed by the surgeon, includes a VAS score of pain walking on level ground and on stairs or inclines, as well as an assessment of alignment, ligament stability, and ROM, along with deductions for flexion contracture or extensor lag.

Only patients aged between 60 and 80 years, with primary knee osteoarthritis and a body mass index less than 30 were included; their procedures occurred in 2013 and 2014. Exclusion criteria included patients with follow-up $<18$ months, patients with systemic diseases with articular commitment (such as lupus, rheumatoid arthritis, etc.), previous knee surgery, contralateral knee arthroplasty and patients unable to adequately answer the questions due to neurological/ psychiatric diseases or other restrictions. All of the patients were submitted to spinal anaesthesia and a pneumatic tourniquet was used in every case. In all cases, an anterior approach was used, with articular transvastus access.

The decision of patellar resurfacing was based on the Outerbridge classification [8]. The patellar component was placed only in Grade IV cases (exposed subchondral bone). In the non-resurfacing group, osteophytes were removed and denervation of the patellar borders was routinely performed with electrocauterisation.

After cementation of the implants (Baumer), the tourniquet was deflated and we proceeded to haemostasis.

After surgery, a Robert Jones bandage was used in every case, and a vacuum drainage system was removed $48 \mathrm{~h}$ after surgery.

Physiotherapy started on day 1 post-op and patients were encouraged to undertake gait training on day 2 . All patients were prescribed at least 20 physiotherapy sessions.

Final KSS was acquired in all patients after 18 months. This score evaluates pain, contractures, range of motion, alignment and stability of the joint. The result is considered excellent if it reaches 80 points. As for the statistical analysis, continuous variables were presented as mean and standard deviation, and compared using the Student $\mathrm{T}$ test. Categorical variables were presented as numbers and percentages. The differences between the groups were evaluated by applying the chi-squared test or Fisher's exact test. The software used for all statistical analysis was SPSS 18.0. Those analyses with type $\alpha$ error $<10 \%$ were considered significant.

This project was accepted by the Research Ethics Committee of Irmadade Santa Casa de Misericórdia de Porto Alegre and was financed by the researchers, with no conflict of interests.

\section{Results}

Both study groups were similar, but the higher mean age in the NPR group must be mentioned, as it is relevant, despite not being statistically significant (69.56 \pm 
6.5 versus $72.52 \pm 5.2 ; p=0.064)$

Of the 60 patients evaluated in the study, none had a KSS $<60$, which could characterise the surgery as unsatisfactory. Patients in both groups presented similar KSS values, with no statistical significance $(\mathrm{RP}=88.36 \pm 9.64 ; \mathrm{NRP}=$ $84.26 \pm 9.44 ; p=0.103)$.

When stratifying the patients into subgroups of results using KSS (poor, fair, good, excellent), we found $84.8 \%$ excellent results in the RP group, versus $59.3 \%$ in the NRP group $(p=0.056)$. These findings have shown no statistical significance $(p<0.05)$, and could have occurred by chance (Table 1$)$.

\section{Discussion}

The ideal management of the patella in TKA is not yet clear. Much controversy surrounds the subject, despite the procedure having been performed for more than 3 decades. The most common complications of patellar resurfacing are: misalignment, instability, fracture of the patella, extensor apparatus lesion, polyethylene erosion and osteolysis.

Loosening of the patellar component can occur in $0.6 \%$ to $4.8 \%$ of cases. Meding et al. reviewed 8531 cases of TKA and found radiographic evidence of loosening in 409 (4.8\%) [9] [10].

Panni et al. reviewed 280 cases with 96 months of follow-up, and found patellofemoral complications in 19 resurfaced cases (7\%) [11]. Many studies showed advantages in keeping the patella without resurfacing in specific conditions, like in young patients (age $<60$ ), non-obese, in the absence of patellofemoral pain prior to TKA, congruent patellar tracking, absence of systemic disease with articular commitment, normal patellar shape and viable cartilage (Outerbridge I, II or III). Kim et al. used these criteria, and found $97.5 \%$ satisfactory results in a 10-year follow-up [12].

Not resurfacing the patella can provide the cartilage and subchondral bone a biological adaptation and remodelling process. This process occurs only with the use of a geometrically designed prosthesis for that purpose [13] [14] [15].

Table 1. Socio-demographic and KSS score.

\begin{tabular}{cccc}
\hline & RP & NRP & $p$ \\
\hline Gender n (\%) & & & 0.178 \\
Male n (\%) & $7(21.2)$ & $8(29.6)$ & \\
Female n (\%) & $26(78.8)$ & $19(70.4)$ & 0.064 \\
Mean age (years) & $69.59 \pm 6.5$ & $72.5 \pm 5.2$ & 0.103 \\
KSS & $88.36 \pm 9.64$ & $84.26 \pm 9.44$ & 0.056 \\
Score & & & \\
Fair & $1(3 \%)$ & $1(3.7 \%)$ & \\
Good & $4(12.1 \%)$ & $10(37 \%)$ & \\
Excelent & $28(84.8 \%)$ & $16(59.3 \%)$ & \\
\hline
\end{tabular}


Rodriguez-Merchan and Gómez-Cardero reviewed 500 TKA cases with and without PR and evaluated the quality of the cartilage (Outerbridge). After 5 years of follow-up, in the group without resurfacing and Outerbridge I, II or III, only one patient $(0.6 \%)$ needed reoperation for resurfacing. As for the Outerbridge IV cases, 10 needed another surgery [16].

Randomised clinical trials are divergent in defining the benefits of patellar resurfacing. Smith et al. found no evidence of benefit of resurfacing in their study [17]. Kahn et al. found benefits of the procedure in patients with previous patellofemoral pain, but limitations in follow-up may leave one to question such results [18].

By evaluating quality of life, Robertsson et al. reviewed 27,372 patients submitted to TKA and found $15 \%$ dissatisfaction in the resurfacing group, compared to $19 \%$ in the other [19]. Bourne and Burnett, and Feller et al., using the Stair Climb Test, registered better results in the not-resurfacing group [20] [21]. Myles et al. and Smith, in two biomechanics studies, were unable to show relevant differences between the two groups.

Schindler reviewed 16 randomised studies comparing TKA with and without resurfacing, totalling 1587 of PR cases and 1620 of NPR cases. No statistical difference was found between the groups in analysing pain and function in 9 studies. Five studies showed slightly better results in resurfacing, and two for not resurfacing [22].

Schindler published 10 prospective studies with bilateral TKA in which one side was resurfaced. After a mean follow-up of 5 years, $47 \%$ of patients referred no preference, $35 \%$ preferred the resurfaced side and $18 \%$ the other [5].

In our study, we found no significant difference in quality of life (KSS) with or without patellar resurfacing. However, when subdividing into groups with different degrees of satisfaction, we have noticed a tendency for more "excellent" results after resurfacing. We cannot ensure the superiority of resurfacing the patella in our study due to short follow-up and restricted number of patients. These findings are concordant to literature on the subject, but it was not yet possible to define whether resurfacing the patella is advantageous to knee osteoarthritis patients or not.

Differences in the design between implants make this evaluation even more difficult, as well as the decision to alter the patellar component of the joint or not. There are many confusing factors involving this matter, turning decisionmaking even harder to surgeons. The main limitations of the present study include being a small retrospective cohort, and short follow-up.

\section{Conclusions}

In spite of not being statistically significant, patellar resurfacing generated more "excellent" results (in regard to Knee Society Score) after 18 months of follow-up in Total Knee Arthroplasty patients.

Patellar resurfacing remains a controversial subject. Larger clinical trials are 
necessary to define whether the procedure is beneficial to patients with Knee Osteoarthritis.

\section{Conflicts of Interests}

The authors claim that there are no conflicts of interest regarding this paper.

\section{References}

[1] Vivan, A.S. and Argimon I.I.L. (2009) Coping Strategies, Functional Difficulties, and Associated Factors in Institutionalized Elderly. Cadernos de Saúde Pública, 25, 436-444. https://doi.org/10.1590/S0102-311X2009000200022

[2] Grotle, M., Garratt, A.M., Klokkerud, M., Løchting, I., Uhlig, T. and Hagen, K.B. (2010) What's in Team Rehabilitation Care after Arthroplasty for Osteoarthritis? Results from a Multicentre, Longitudinal Study Assessing Structure, Process, and Outcome. Physical Therapy, 90, 121-131. https://doi.org/10.2522/ptj.20080295

[3] Rorabeck, C.H., Dorr, L.D., Hofmann, A.A., Insall, J.N., Keblish, P.A., Krackow, K.A., et al. (1995) Controversial Issues in Knee Arthroplasty. Orthopaedics, 18, 905914.

[4] Burnett, R.S. and Bourne, R.B. (2003) Indications for Patellar Resurfacing in Total Knee Arthroplasty. The Journal of Bone and Joint Surgery, 85, 728-745. https://doi.org/10.2106/00004623-200304000-00022

[5] Schindler, O.S. (2012) The Controversy of Patellar Resurfacing in Total Knee Arthroplasty: Ibisne in Mediotutissimus? Knee Surgery, Sports Traumatology, Arthroscopy, 20, 1227-1244. https://doi.org/10.1007/s00167-012-1985-7

[6] Robertsson, O., Knutson, K., Lewold, S. and Lidgren, L. (2001) The Swedish Knee Arthroplasty Register 1975-1997: An Update with Special Emphasis on 41,223 Knees Operated on in 1988-1997. Acta Orthopaedica Scandinavica, 72, 503-513. https://doi.org/10.1080/000164701753532853

[7] Marx, F.C., Oliveira, L.M., Bellini, C.G. and Ribeiro, M.C.C. (2006) Tradução e validação cultural do questionário algofuncional de Lequesne para osteoartrite de joelhos e quadris para a Língua Portuguesa. Revista Brasileira de Reumatologia, 46, 253-260. https://doi.org/10.1590/S0482-50042006000400004

[8] Outerbridge, R.E. (1961) The Aetiology of Chondromalacia Patellae. The Journal of Bone and Joint Surgery, 43, 752-757.

[9] Meding, J.B., Fish, M.D., Berend, M.E., Ritter, M.A. and Keating, E.M. (2008) Predicting Patellar Failure after Total Knee Arthroplasty. Clinical Orthopaedics and Related Research, 466, 2769-2774. https://doi.org/10.1007/s11999-008-0417-y

[10] Mochizuki, R.M. and Schurman, D.J. (1979) Patellar Complications Following Total Knee Arthroplasty. The Journal of Bone and Joint Surgery, 61, 879-883. https://doi.org/10.2106/00004623-197961060-00012

[11] Panni, A.S., Cerciello, S., Regno, C.D., Felici, A. and Vasso, M. (2014) Patellar Resurfacing Complications in Total Knee Arthroplasty. International Orthopaedics, 38, 313-317. https://doi.org/10.1007/s00264-013-2244-3

[12] Kim, B.S., Reitman, R.D., Schai, P.A. and Scott, R.D. (1999) Selective Patellar Non-Resurfacing in Total Knee Arthroplasty. 10 Year Results. Clinical Orthopaedics and Related Research, No. 367, 81-88.

[13] Smith, S.R., Stuart, P. and Pinder, I.M. (1989) Non-Resurfaced Patella in Total Knee Arthroplasty. The Journal of Arthroplasty, 4, S81-S86. 
[14] Keblish, P.A., Varma, A.K. and Greenwald, A.S. (1994) Patellar Resurfacing or Retention in Total Knee Arthroplasty. A Prospective Study of Patients with Bilateral Replacements. The Journal of Bone and Joint Surgery, 76, 930-937.

[15] Ma, H.M., Lu, Y.C., Kwok, T.G., Ho, F.Y., Huang, C.Y. and Huang, C.H. (2007) The Effect of the Design of the Femoral Component on the Conformity of the Patellofemoral Joint in Total Knee Replacement. The Journal of Bone and Joint Surgery, 89, 408-412. https://doi.org/10.1302/0301-620X.89B3.18276

[16] Rodríguez-Merchán, E.C. and Gómez-Cardero, P. (2010) The Outer Bridge Classification Predicts the Need for Patellar Resurfacing in TKA. Clinical Orthopaedics and Related Research, 468, 1254-1257. https://doi.org/10.1007/s11999-009-1123-0

[17] Smith, A.J., Lloyd, D.G. and Wood, D.J. (2006) A Kinematic and Kinetic Analysis of Walking after Total Knee Arthroplasty with and without Patellar Resurfacing. Clinical Biomechanics, 21, 379-386.

[18] Khan, A. and Pradhan, N. (2012) Resultados de artroplastia total de joelho com e sem implante de recapeamento (resurfacing) patellar. Acta Ortopedica Brasileira, 20, 300-302. https://doi.org/10.1590/S1413-78522012000500011

[19] Robertsson, O., Dunbar, M., Pehrsson, T., Knutson, K. and Lidgren, L. (2000) Patient Satisfaction after Knee Arthroplasty: A Report on 27,372 Knees Operated on between 1981 and 1995 in Sweden. Acta Orthopaedica Scandinavica, 71, 262-267. https://doi.org/10.1080/000164700317411852

[20] Bourne, R.B. and Burnett, R.S. (2004) The Consequences of Not Resurfacing the Patella. Clinical Orthopaedics and Related Research, 428, 166-169. https://doi.org/10.1097/01.blo.0000147137.05927.bf

[21] Feller, J.A., Bartlett, R.J. and Lang, D.M. (1996) Patellar Resurfacing versus Retention in Total Knee Arthroplasty. The Journal of Bone and Joint Surgery, 78, 226228.

[22] Myles, C.M., Rowe, P.J., Nutton, R.W. and Burnett, R. (2006) The Effect of Patella Resurfacing in Total Knee Arthroplasty on Functional Range of Movement Measured by Flexible Electrogoniometry. Clinical Biomechanics, 21, 733-739.

\section{Submit or recommend next manuscript to SCIRP and we will provide best service for you:}

Accepting pre-submission inquiries through Email, Facebook, LinkedIn, Twitter, etc. A wide selection of journals (inclusive of 9 subjects, more than 200 journals) Providing 24-hour high-quality service User-friendly online submission system Fair and swift peer-review system Efficient typesetting and proofreading procedure Display of the result of downloads and visits, as well as the number of cited articles Maximum dissemination of your research work

Submit your manuscript at: http://papersubmission.scirp.org/

Or contact ojo@scirp.org 